\title{
A subset of neutrophils in human systemic inflammation inhibits $T$ cell responses through Mac-1
}

\author{
Janesh Pillay, ${ }^{1}$ Vera M. Kamp, ${ }^{1}$ Els van Hoffen, ${ }^{2}$ Tjaakje Visser, ${ }^{3}$ Tamar Tak, ${ }^{1}$ Jan-Willem Lammers, ${ }^{1}$ \\ Laurien H. Ulfman, ${ }^{1}$ Luke P. Leenen, ${ }^{3}$ Peter Pickkers, ${ }^{4}$ and Leo Koenderman ${ }^{1}$ \\ ${ }^{1}$ Department of Respiratory Medicine, ${ }^{2}$ Department of Dermatology/Allergology, and ${ }^{3}$ Department of Surgery, University Medical Center Utrecht, \\ Utrecht, The Netherlands. ${ }^{4}$ Department of Intensive Care, Radboud University Nijmegen Medical Center, Nijmegen, The Netherlands.
}

\begin{abstract}
Suppression of immune responses is necessary to limit damage to host tissue during inflammation, but it can be detrimental in specific immune responses, such as sepsis and antitumor immunity. Recently, immature myeloid cells have been implicated in the suppression of immune responses in mouse models of cancer, infectious disease, bone marrow transplantation, and autoimmune disease. Here, we report the identification of a subset of mature human neutrophils $\left(\mathrm{CD} 11 \mathrm{c}^{\text {bright }} / \mathrm{CD} \mathrm{L}^{\mathrm{dim}} / \mathrm{CD} 11 \mathrm{~b}^{\text {bright }} / \mathrm{CD} 16^{\text {bright }}\right)$ as what we believe to be a unique circulating population of myeloid cells, capable of suppressing human $T$ cell proliferation. These cells were observed in humans in vivo during acute systemic inflammation induced by endotoxin challenge or by severe injury. Local release of hydrogen peroxide from the neutrophils into the immunological synapse between the neutrophils and $T$ cells mediated the suppression of $T$ cell proliferation and required neutrophil expression of the integrin Mac-1 ( $\alpha \mathrm{M} \beta 2)$. Our data demonstrate that suppression of $\mathrm{T}$ cell function can be accomplished by a subset of human neutrophils that can be systemically induced in response to acute inflammation. Identification of the pivotal role of neutrophil Mac-1 and ROS in this process provides a potential target for modulating immune responses in humans.
\end{abstract}

\section{Introduction}

Immune suppression is essential in immune regulation, but can be detrimental in various pathological conditions. Classically, lymphoid cells play a major role in regulating immune responses. Recently, however, a role for myeloid cells that mediate immune suppression has gained much attention (1). A heterogeneous group of cells, referred to as myeloid-derived suppressor cells (MDSCs), has been shown to directly suppress $\mathrm{T}$ cell functions in murine models of cancer, infectious diseases, bone marrow transplantation, and autoimmune diseases (2-5). The immunesuppressive characteristics of these MDSCs are thought to limit the effectiveness of anticancer vaccines (6). Murine MDSCs consist of immature myeloid cells of monocytic and granulocytic lineages (5). The majority of research concerning MDSCs has focused on murine tumor models. Several mechanisms are described to regulate suppression of $\mathrm{T}$ cell proliferation in these models. In the majority of models, arginase I is associated with MDSC function. Additionally, also, inhibition via ROS, TGF- $\beta$, and IL-10 has been described (7). In mice, MDSCs with a granulocytic origin suppressed $\mathrm{T}$ cell proliferation via a ROS-mediated mechanism (8). In humans, immature myeloid and granulocytic MDSCs have been identified in patients with metastatic cancer (9-11). In agreement with murine models, these cells suppress $\mathrm{T}$ cell functions through an arginase I-dependent mechanism (12). Few papers describe the involvement of ROS in human MDSCs $(13,14)$. Relatively little is known about human MDSCs compared with their murine counterparts, which greatly limits our understanding of their mechanism of suppression in humans.

Authorship note: Janesh Pillay and Vera M. Kamp contributed equally to this work. Conflict of interest: The authors have declared that no conflict of interest exists. Citation for this article: JClin Invest. 2012;122(1):327-336. doi:10.1172/JCI57990.
Therefore, it is essential to gain more insight into the occurrence and mechanisms of suppression by human MDSCs.

Apart from their occurrence in chronic inflammation, MDSCs have been shown to suppress lymphocyte responses in a murine model of sepsis (15). Also, in humans, the concept is emerging that acute inflammation can result in immune suppression (16). This suppression is characterized by an inadequate $\mathrm{T}$ cell response, which can lead to opportunistic infections and reactivation of latent viruses $(17,18)$. So far, the role of human MDSCs in acute inflammation has not been evaluated.

Human acute inflammation results in the mobilization of large amounts of mature and immature neutrophils, which are traditionally viewed as effector cells important in combating infections. We hypothesize that the (immature) neutrophils released during acute inflammation fulfill the role of MDSCs and suppress the immune response.

To test this hypothesis, we induced such inflammation by systemic challenge with LPS (by i.v. injection of $2 \mathrm{ng} / \mathrm{kg}$ E. coli LPS) in healthy volunteers (19).

\section{Results}

Appearance of a neutrophil subset after i.v. administration of LPS in bumans. First, we determined the phenotype of circulating neutrophils after LPS challenge. The left panel of Figure 1A depicts a flow cytometer dot plot, showing uniform expression of CD16 and CD62L by normal granulocytes before LPS administration. The CD16-negative cells were eosinophils. After LPS challenge, a marked decrease was seen in circulating eosinophils (Figure 1A, right panel) in peripheral blood. As previously described, a marked neutrophilia was induced (20). At 3 hours after LPS administration, the pool of circulating neutrophils consisted of at least 3 morphological phenotypes (Figure 1A, right panel). At this time point, banded 
A Before LPS administration

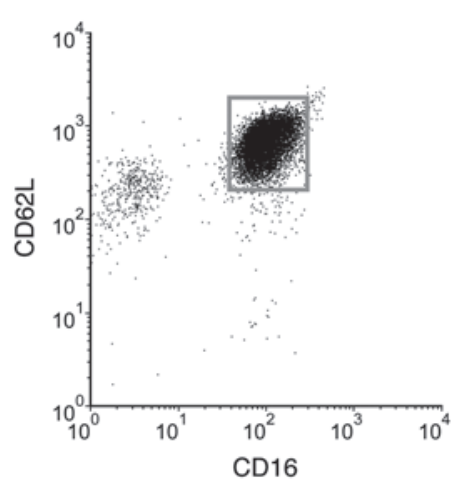

\section{B}

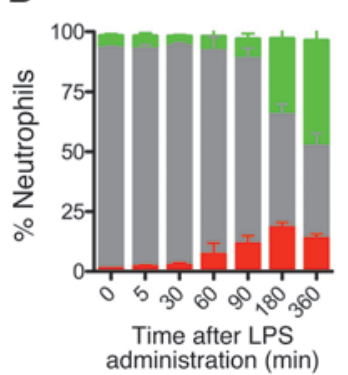

C
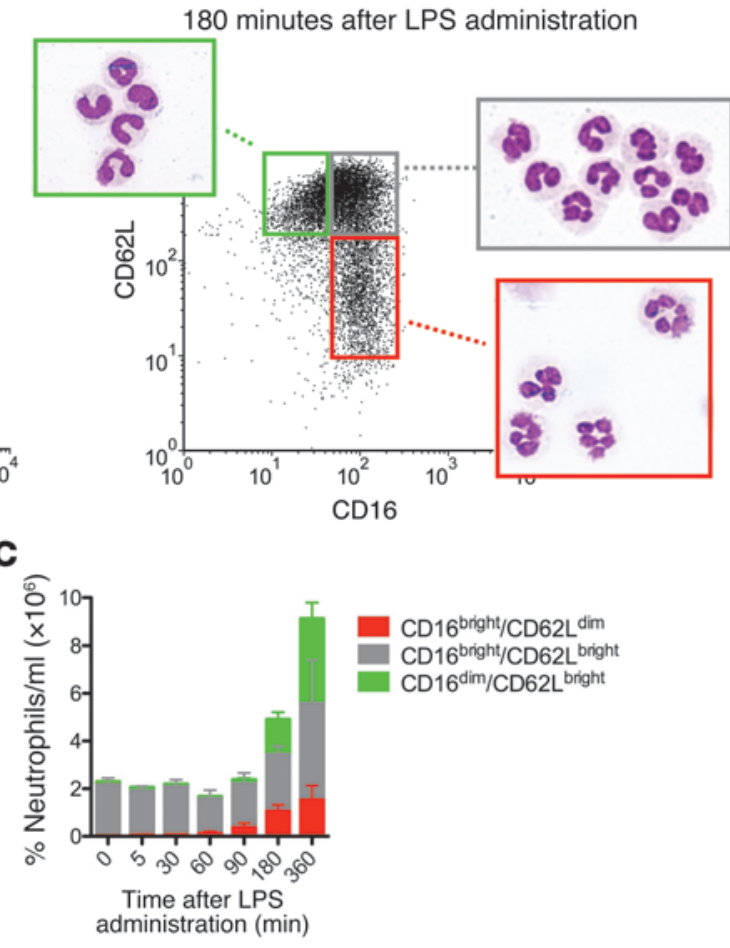

Figure 1

Neutrophil subsets after LPS administration. (A) Neutrophils were stained for CD16 and CD62L before and 180 minutes after LPS administration. Before LPS administration, neutrophils formed one population; the CD16 low cells are eosinophils. At 180 minutes after LPS administration, 2 distinct neutrophil subsets were identified. Subsets were FACS sorted, and cytospins were made and stained with May-Grunwald Giemsa. Original magnification, $\times 100$. (B) Neutrophils were stained for CD16 and CD62L at different time points; time point 0 is before LPS challenge. Percentages of neutrophil subsets were calculated from flow cytometry data. Data are expressed as mean \pm SEM; $n=7$. (C) Absolute counts of neutrophil subsets were calculated using the percentage of the subsets and the absolute neutrophil counts (mean \pm SEM; $n=7$ ).
(CD16 dim/CD62 $\mathrm{L}^{\text {bright }}$ ) neutrophils appeared in the circulation, most likely released from the bone marrow. In parallel, CD16 bright/ CD62 $\mathrm{L}^{\mathrm{dim}}$ neutrophils were found in the circulation, displaying a hypersegmented nuclear morphology. The CD16 $6^{\mathrm{dim}} / \mathrm{CD} 62 \mathrm{~L}^{\text {bright }}$ and CD $16^{\text {bright }} / \mathrm{CD} 62 \mathrm{~L}^{\text {dim }}$ cells were not found in healthy donors before LPS administration (Figure 1A, left panel). These populations comprised $20 \%-25 \%$ and $10 \%-15 \%$ of total circulating neutrophils, respectively (Figure 1B). The third population, CD16 $6^{\text {bright }} /$ CD62 $\mathrm{L}^{\text {bright }}$ cells, fell in the same gate as the normal cells in the left panel of Figure 1A. As a marked neutrophilia was present, the CD16 ${ }^{\mathrm{dim}}$ and CD62 $\mathrm{L}^{\mathrm{dim}}$ subsets comprised a substantial absolute number of circulating leukocytes (Figure 1C).

Characterization of neutrophil subsets after i.v. LPS administration. The neutrophil subsets displayed marked differences in expression of surface markers. The CD62 $\mathrm{L}^{\mathrm{dim}}$ neutrophils showed an increased expression of CD11b, CD11c, and CD54 but an equal expression of CD88 compared with that of CD16 dim neutrophils (Figure 2A). Supplemental Table 1 (supplemental material available online with this article; doi:10.1172/JCI57990DS1) shows expression of 20 additional markers that were assayed. CD62 L dim neutrophils showed higher expression of most surface markers assayed compared with that of the other neutrophil subsets. Upregulation of expression of CD11b on this subpopulation might be due to cellular activation induced by LPS administration, as this integrin is sensitive for - and is rapidly induced by - soluble stimuli. A more stringent marker for activated cells is ICAM-1 (CD54), as this is mostly found on extravasated neutrophils (21) and in vitro is only upregulated after prolonged cytokine stimulation (data not shown).

Apart from the differences in expression of surface markers, these 2 distinct populations also displayed functional heterogeneity. CD16 $6^{\mathrm{dim}}$-banded neutrophils showed a higher rate of survival after 24 hours in culture compared with that of the CD62L dim neutrophils, which displayed a similar, rapid apoptosis rate to that of normal $(t=0)$ neutrophils (Figure $2 \mathrm{~B}$ ). Activation of the NADPH oxidase, as measured by extracellular $\mathrm{H}_{2} \mathrm{O}_{2}$ production, was approximately 3-fold higher in CD62 $\mathrm{L}^{\mathrm{dim}}$ neutrophils compared with that in healthy control neutrophils and the CD16 ${ }^{\mathrm{dim}}$ subset neutrophils after ex vivo stimulation with platelet-activating factor (PAF) and $\mathrm{N}$-formyl-methionyl-leucyl-phenylalanine (fMLF) (Figure 2C).

CD62L dim $/ C D 11 c^{\text {bright }}$ neutrophils suppress lymphocyte activation. As both mouse and human MDSC populations have been described to contain neutrophils (1), we examined the capacity of our distinct neutrophil populations to suppress phytohemagglutinin-induced (PHA-induced) and CD3/CD28-induced lymphocyte activation. Surprisingly, the CD62 $\mathrm{L}^{\mathrm{dim}}$ hypersegmented neutrophils potently suppressed $\mathrm{T}$ cell proliferation in a dose-dependent manner both upon PHA and upon CD3/CD28 stimulation (Figure 3, A and B). In marked contrast, CD16 $6^{\mathrm{dim}}$-banded neutrophils and neutrophils isolated from blood before LPS administration were not able to suppress lymphocyte proliferation (Figure 3, A and B). Around $80 \%$ of the cocultured neutrophils were apoptotic after 24 hours (Supplemental Figure 1). The CD16 ${ }^{\text {dim }}$ neutrophil subset showed fewer living cells in cocultures (Supplemental Figure 1) compared with those in single cultures (Figure 2B), which might be due to cytokine environment.

As PHA and CD3/CD28 lymphocyte responses are model systems for polyclonal $\mathrm{T}$ cell proliferation, we tested a more physiological response using tetanus toxoid. For this, we used isolated PBMCs from healthy volunteers who had received a tetanus booster vaccination less than 5 years ago. Responses induced by tetanus toxoid were suppressed to a similar extent as the PHA-induced responses (Figure 3C).

The suppressive effect was not explained by induction of $\mathrm{T}$ cell apoptosis through neutrophil cytotoxicity, as both suppressive (CD62 $\mathrm{Lim}^{\mathrm{dim}}$ ) and nonsuppressive (CD16 $6^{\mathrm{dim}}$ ) neutrophil subsets showed similar amounts of T cell apoptosis in our cocultures (Figure 3D). 
A
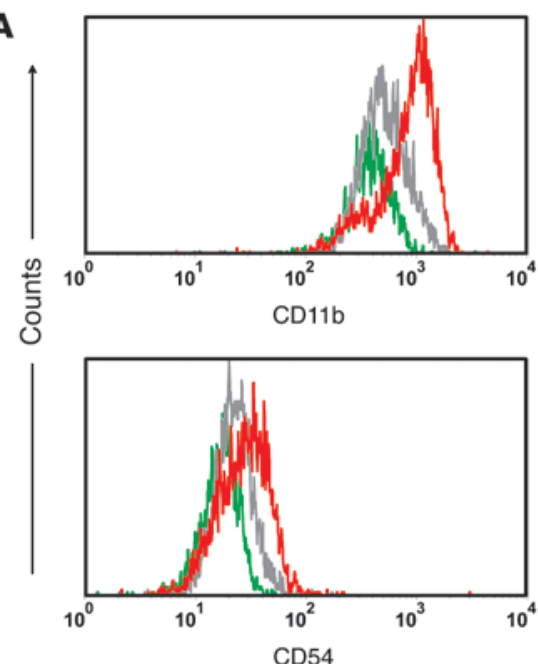

CD54

B

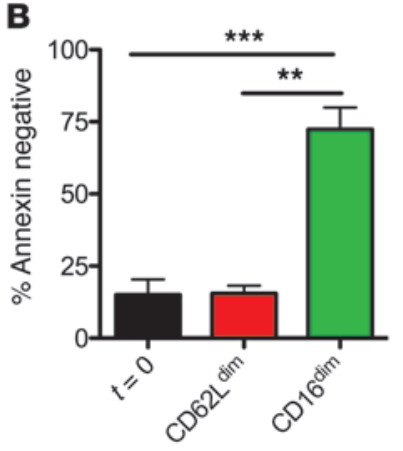

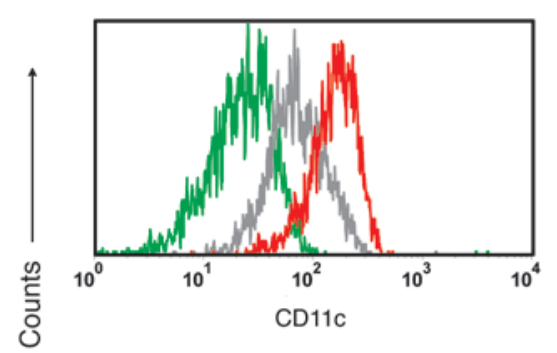

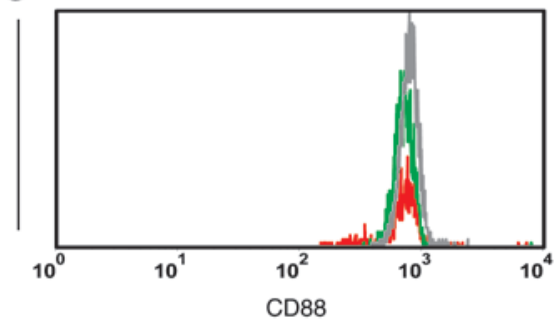

C

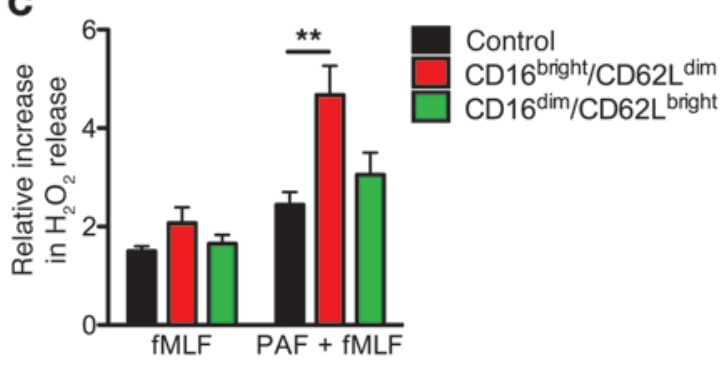

\section{Figure 2}

Neutrophil phenotype after LPS administration (A) Neutrophils were stained for CD16 and CD62L to discriminate between the subsets. Additionally, they were stained with CD11b, CD11c, CD54, and CD88. Mean fluorescence intensity is depicted. Red lines depict CD16 bright/ CD62Ldim; gray lines depict CD16 ${ }^{\text {bright/ }}$ CD62 bright; green lines depict CD16 dim/ CD62Lbright. Graphs are representative of 5 experiments. (B) Neutrophil survival after 24 hours. Neutrophils subsets were FACS sorted, and cells were incubated for 24 hours at $37^{\circ} \mathrm{C}, 5 \% \mathrm{CO}_{2}$; after incubation, they were stained with annexin $\mathrm{V}$ PE for 15 minutes and measured by flow cytometry. Data are expressed as the percentage of annexin $\mathrm{V}$-negative, living cells (mean \pm SEM; $n=5$ ). (C) Relative increase in $\mathrm{H}_{2} \mathrm{O}_{2}$ in unsorted neutrophils measured by flow cytometry with DHR. Neutrophil subsets are visualized with CD16 and CD62L staining. Cells were stimulated with $\mathrm{PMLF}\left(10^{-6} \mathrm{M}\right)$ and PAF $\left(10^{-6} \mathrm{M}\right)$ for 15 minutes. Neutrophils from healthy controls were used as a control. Graph shows relative increase in $\mathrm{H}_{2} \mathrm{O}_{2}$ release (mean $\pm \mathrm{SEM} ; n=7$ ). ${ }^{\star \star} P<0.005 ;{ }^{* *} P<0.001$.
$T$ cell phenotype after coculture with $C D 62 L^{\text {dim }}$ neutrophils. Subsequently, the $\mathrm{T}$ cell phenotype after coculture was analyzed. No significant differences were found in CD4 and CD8 expression (Figure 4, A and B) after 2 days of coculture with CD62L dim neutrophils. ELISAs were performed measuring cytokines in the supernatant of 4 day PHA-stimulated cocultures. Both IL-4 and IL-10 levels were below the detection level in all conditions. IFN- $\gamma$ (Figure 4C) and IL-13 (Figure 4D) production was lower in cocultures with $\mathrm{CD} 62 \mathrm{~L}^{\mathrm{dim}}$ neutrophils compared with that in the cultures in the presence of normal and CD16 ${ }^{\text {dim }}$ neutrophils (Figure 4, C and D). Intracellular cytokine stains showed that neutrophil cocultures did not influence the percentage of IFN- $\gamma$-producing (Figure 4, E and G) or IL-4-producing (Figure 4, F and G) cells. These data suggested that neutrophils did not inhibit a subset of IFN- $\gamma$ - or IL-4-producing lymphocytes but rather inhibited total polyclonal proliferation. While the percentage of cytokine-producing cells stayed constant, inhibition of proliferation resulted in fewer $T$ cells per well after 4 days. As a result, the total cytokine production is decreased. There was no skewing toward Th1 (IFN- $\gamma$ ) or Th2 (IL-4, IL-13) due to coculture with neutrophils.

CD62L ${ }^{\text {dim }} / C D 11 c^{\text {bright }}$ neutrophil-induced $T$ cell suppression requires neutrophil Mac-1. In murine models, MDSC T cell suppression can be mediated by arginase I. L-arginine has been shown to inhibit the effect of arginase I-mediated suppression (22). However supraphysiological concentrations of L-arginine did not affect CD62 L dim neutrophil-induced suppression. This showed that arginase I was not used for T cell suppression by this subset of CD62 Lim neutrophils (Figure 5A). Neutrophils have also been shown to secrete IL-10 and TGF- $\beta$, which play an important role in $\mathrm{T}$ cell suppression. However, antagonism of these factors revealed no role for these cytokines in our system (Figure 5A). Next, we investigated whether a direct contact between lymphocytes and CD62 $\mathrm{L}^{\mathrm{dim}}$ neutrophils was needed, using a transwell system separating the cell suspensions. In this system, neutrophils lost their suppressive capacity compared with that of neutrophils that were not separated, indicating that cellular proximity is needed between neutrophils and lymphocytes (Figure 5B).

In addition to arginase I, ROS have been implicated in immune suppression by MDSCs (23). The production of $\mathrm{O}_{2}^{-}$by the membrane-bound NADPH oxidase is an essential antimicrobial function of neutrophils (24). $\mathrm{H}_{2} \mathrm{O}_{2}$, which is a downstream metabolite of $\mathrm{O}_{2}^{-}$, has been shown to modulate $\mathrm{T}$ cell responses through various mechanisms $(25,26)$. Therefore, we examined whether $\mathrm{H}_{2} \mathrm{O}_{2}$ production contributed to the suppressive effects of this neutrophil subset. Indeed, the $\mathrm{H}_{2} \mathrm{O}_{2}$ scavenger catalase was able to partially recover the inhibition of $\mathrm{T}$ cell suppression by $20 \%$ when added to the cocultures (Figure 5C). Next, as neutrophils are capable of producing large quantities of hydrogen peroxide, we examined whether suppression of $\mathrm{T}$ cell proliferation was due to massive release of $\mathrm{H}_{2} \mathrm{O}_{2}$. Cocultures were supplemented with the fluorescent probe Amplex Red, which is used to detect extracellular $\mathrm{H}_{2} \mathrm{O}_{2}$. In these cultures, no extracellular release of $\mathrm{H}_{2} \mathrm{O}_{2}$ was observed (Figure 5D). As a control, PAF/fMLF was added to the cocultures, which showed that despite low numbers of neutrophils in the cocultures, an extracellular release of $\mathrm{H}_{2} \mathrm{O}_{2}$ could be detected (Figure 5D). 
A

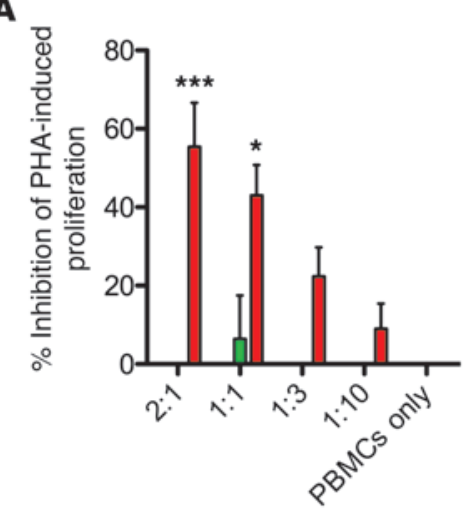

C

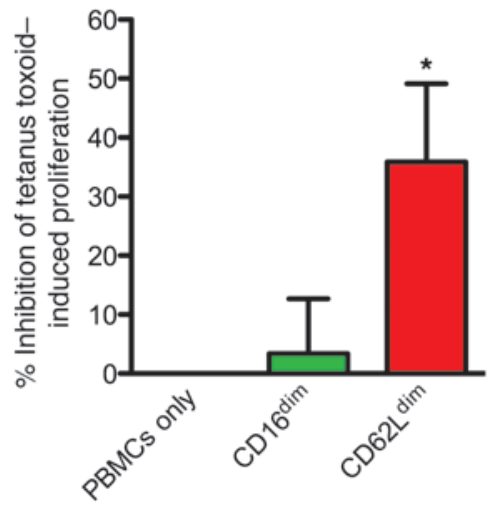

B
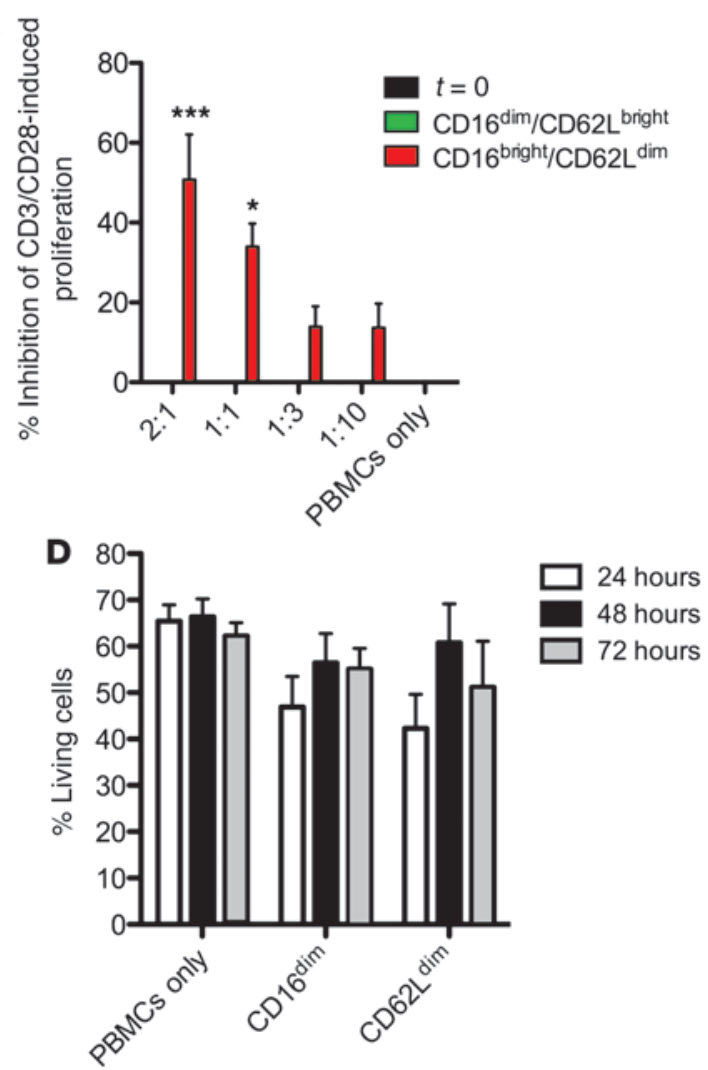

Figure 3

T cell proliferation after incubation with neutrophil subsets. Blood was drawn 180 minutes after LPS administration, neutrophils were stained for CD16 and CD62L, and subsets were sorted. PBMCs were isolated from blood drawn before LPS administration and isolated by ficoll gradient separation. T cell proliferation was measured by [3H]thymidine incorporation. (A) PBMCs were stimulated with PHA (10 $\mu \mathrm{g} / \mathrm{ml})$ and incubated with different concentrations of the neutrophil subsets for 4 days. Data are depicted as the percentage inhibition of proliferation (mean \pm SEM; $n=7$ ). (B) PBMCs were stimulated with CD3 at $0.15 \mu \mathrm{g} / \mathrm{m} / \mathrm{CD} 28$ at $1 \mu \mathrm{g} / \mathrm{ml}$ and incubated with different concentrations of the neutrophil subsets for 4 days. Data are presented as mean \pm SEM; $n=7$. (C) PBMCs from healthy volunteers who had received a tetanus booster vaccination less than 5 years ago were stimulated with tetanus toxoid, incubated with CD62L dim or CD16 dim neutrophils, and added in a 2:1 neutrophil-to-lymphocyte ratio for 4 days. Data are depicted as the percentage inhibition of proliferation (mean $\pm \mathrm{SEM} ; n=10$ ). (D) T cell apoptosis in neutrophil cocultures. Neutrophils were added in a 2:1 ratio in culture conditions described for the T cell proliferation cultures. At various time points, cells were stained with CD3 FITC and annexin V PE, and apoptosis was measured by gating the CD3-positive cells by flow cytometry. Data are depicted as the percentage of living cells (mean \pm SEM; $n=4$ ). ${ }^{*} P<0.05 ;{ }^{* \star *} P<0.001$.

The necessity of cellular proximity of neutrophils and $\mathrm{T}$ cells, as observed in the transwell assay, and the ability of catalase to prevent suppression, combined with a lack of an overall oxidative environment, led us to hypothesize that neutrophils locally deliver $\mathrm{H}_{2} \mathrm{O}_{2}$ to T cells. Neutrophils are capable of creating immunological synapses using integrins for efficient phagocytosis of opsonized bacteria in which the integrin $\alpha \mathrm{M} \beta 2$ (Mac-1) plays an important role, and $\mathrm{H}_{2} \mathrm{O}_{2}$ can be produced within these synapses (27). In such synapses, availability of catalase could have been limited, explaining the partial effect of catalase as described above. Leukocyte integrins are pivotal in mediating cellular contact, creating platforms of cellular communication (28). Indeed, blocking Mac-1 using monoclonal antibody 44a in our cocultures resulted in 35\% recovery of $\mathrm{T}$ cell suppression (Figure $5 \mathrm{C}$ ). As $\mathrm{T}$ cells require functional $\alpha \mathrm{L} \beta 2$ (LFA-1) integrin for effective proliferation, specific blocking of LFA- 1 or total $\beta 2$ integrin could not be performed, since $\mathrm{T}$ cell proliferation was potently disrupted. Although our suppressive neutrophil subset was high in CD11c ( $\alpha X \beta 2)$ expression, blocking CD11c in our cocultures did not affect $\mathrm{T}$ cell proliferation (data not shown). Combination of both catalase and $44 \mathrm{a}$ resulted in a $62 \%$ decrease of CD $62 \mathrm{~L}^{\mathrm{dim}}$ neutrophil-induced inhibition of $\mathrm{T}$ cell proliferation (Figure 5C). This demonstrated that blocking of $\alpha \mathrm{M}(\mathrm{CD} 11 \mathrm{~b} /$ clone $44 \mathrm{a})$ in combination with scavenging of $\mathrm{H}_{2} \mathrm{O}_{2}$ had an additive effect.

These data show that local delivery of $\mathrm{H}_{2} \mathrm{O}_{2}$ to $\mathrm{T}$ cells results in decreased proliferation. The immune-suppressive effect could be mediated by monocytes, as these cells have been reported to interact with neutrophils. Therefore, we depleted monocytes from the PBMC fraction before adding neutrophils and PHA. This did not alter the suppressive characteristics of the CD62 $\mathrm{L}^{\mathrm{dim}}$ neutrophils and demonstrated that monocytes were not required for the suppressive phenotype of these neutrophils (Supplemental Figure 2).

We next visualized the interaction between CD62 $\mathrm{L}^{\mathrm{dim}}$ neutrophils and $\mathrm{T}$ cells in a real-time imaging set up, using a culture medium containing the Amplex Red probe for visualization of $\mathrm{H}_{2} \mathrm{O}_{2}$. Addition of HRP allowed for visualization of localized $\mathrm{H}_{2} \mathrm{O}_{2}$ production. Monocytes were depleted from the PBMCs for these experiments. Local release of $\mathrm{H}_{2} \mathrm{O}_{2}$ was observed at the sites of interaction 
A

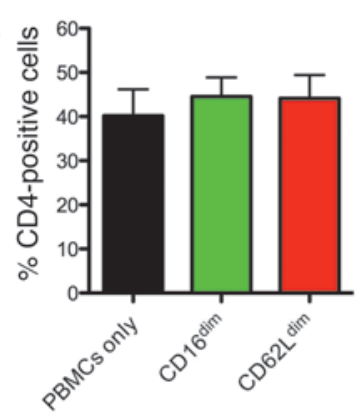

E

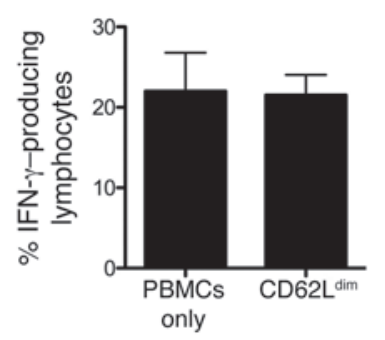

B

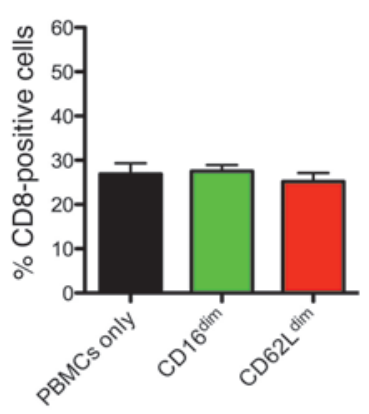

F

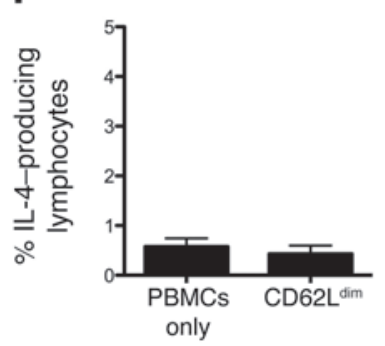

C

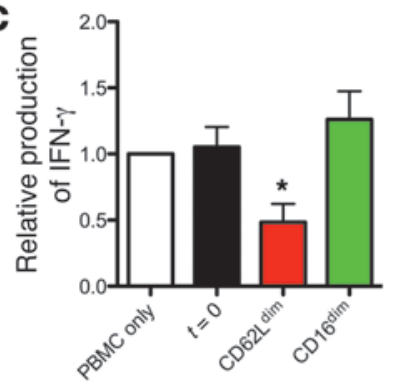

G

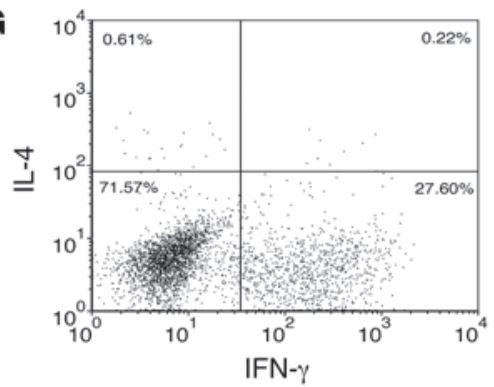

Figure 4

Lymphocyte phenotype after neutrophil coculture. PBMCs were incubated with or without CD62Ldim and CD16 dim neutrophils added in a 2:1 ratio. The cells were stimulated with PHA. (A and B) After 2 days of coculture, cells were stained for flow cytometry, and the percentages of (A) CD4-positive and (B) CD8-positive T cells was determined. Data are presented as mean \pm SEM; $n=3$. (C and D) After 4 days, (C) IFN- $\gamma$ and (D) IL-13 production was measured in the supernatant of the coculture using a sandwich ELISA. Data are presented as relative production of IFN- $\gamma$ or IL-13 compared with that of PBMCs only (mean \pm SEM; $n=6$ ). (E-G) The percentage IFN- $\gamma-$ and IL-4-producing T cells was measured by intracellular cytokine staining. PBMCs were stained for CD4/CD8 and intracellular IFN- $\gamma$ and IL-4 after 2 days of coculture Depicted are (E) the percentage IFN- $\gamma$ - or (F) IL-4-producing lymphocytes. Data are presented as mean $\pm \mathrm{SEM} ; n=4$. An example of the staining is shown in G. Numbers indicate the percentages of cells in each gate. ${ }^{\star} P<0.05$.

between neutrophils and lymphocytes (Figure 6A). Figure 6B shows the same interaction as Figure 6A, and further analysis showed that the Amplex Red signal colocalized with the CD16-labeled neutrophil membrane (Figure 6B). These interactions were of a short and transient nature, lasting no longer than 4 minutes, as visualized in time-lapse recordings (Figure 6C and Supplemental Video 1). $\mathrm{H}_{2} \mathrm{O}_{2}$ positive spots were quantified using several hours of time-lapse recordings. The mean number of $\mathrm{H}_{2} \mathrm{O}_{2}$ spots per 1,000 cells in 5 hours was $133 \pm 14$ spots in the CD62 $\mathrm{L}^{\mathrm{dim}}$ subset, compared with 33 \pm 17 spots in the CD16 $6^{\mathrm{dim}}$ subset (Figure 6D). This could be reduced to $62 \pm 30$ spots by adding a Mac-1-blocking antibody (44a) to the coculture with CD62L dim neutrophils.

Identification of suppressive neutrophils in buman systemic inflammation induced by injury. Finally, because neutrophils are sensitive to ex vivo manipulation, we minimized manipulation and assessed $\mathrm{T}$ cell suppression in total leukocytes as a control. Three hours after LPS, total leukocytes were used, containing $85 \%$ neutrophils, $15 \%$ lymphocytes, and less than $1 \%$ monocytes. Addition of Mac-1-blocking $(\alpha \mathrm{M} / \mathrm{CD} 11 \mathrm{~b}-\mathrm{blocking})$ antibodies to total leukocytes increased $\mathrm{T}$ cell proliferation after PHA stimulation. This showed that unmanipulated neutrophils were capable of suppressing $\mathrm{T}$ cell proliferation in a Mac-1-dependent fashion (Supplemental Figure 3). Healthy controls showed no increase in $\mathrm{T}$ cell proliferation after addition of Mac-1-blocking antibodies (data not shown). Neutrophil apoptosis in this assay was very low (Supplemental Figure 4); after 96 hours, $43 \%-61 \%( \pm 4 \%-7 \%)$ of annexin-negative cells were present in the different culture conditions. There were no significant differences in survival between the different culture conditions.
This total leukocyte model system allowed us to assess the occurrence of Mac-1-induced $\mathrm{T}$ cell suppression in patients suffering from acute systemic inflammation. Severely injured patients showed the occurrence of a similar CD62 $\mathrm{L}^{\mathrm{dim}}$ neutrophil subset immediately after admission ( $<12$ hours) to our hospital (Figure $7 \mathrm{~A})$. Five patients were sampled, and all patients showed the occurrence of the CD62L dim neutrophil subset. The presence of Mac-1induced suppression was demonstrated by the increase in cell count and IFN- $\gamma$ production induced by PHA upon addition of blocking antibody 44a (Figure 7, B and C). Blocking CD11c as a control did not induce increases in proliferation and IFN- $\gamma$ production.

\section{Discussion}

This study reports the identification of a human neutrophil subset with a distinct functionality. A mature neutrophil subset released into the circulation during severe inflammation suppresses $\mathrm{T}$ cell activation. This suppression requires specific delivery of $\mathrm{H}_{2} \mathrm{O}_{2}$ into the immunological synapse in a Mac-1-dependent (CD11b/CD18dependent) manner.

Neutrophils are generally considered to be a homogenous population. Only a few studies have addressed their potential heterogeneity, which has mainly been attributed to release of immature neutrophils from the bone marrow $(20,29)$. In inflammation, this heterogeneity has only been described in the context of their generally accepted antimicrobial functions $(30,31)$.

Our work is the first to our knowledge to show a distinct human neutrophil phenotype during acute inflammation with an immunesuppressive capacity. These cells display a hypersegmented nuclear 
A

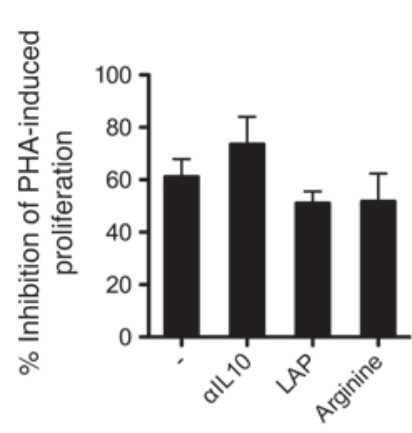

D

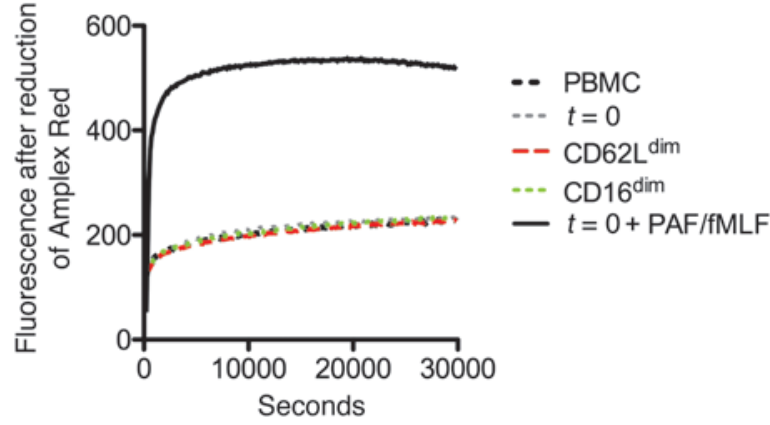

B

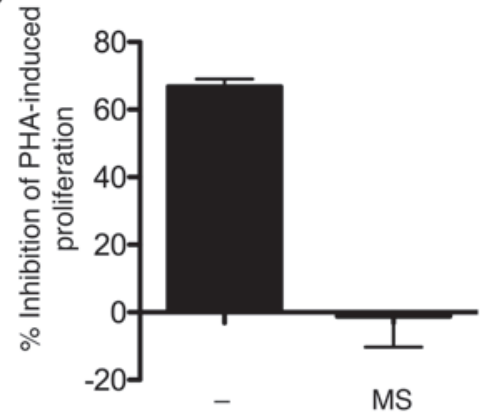

MS

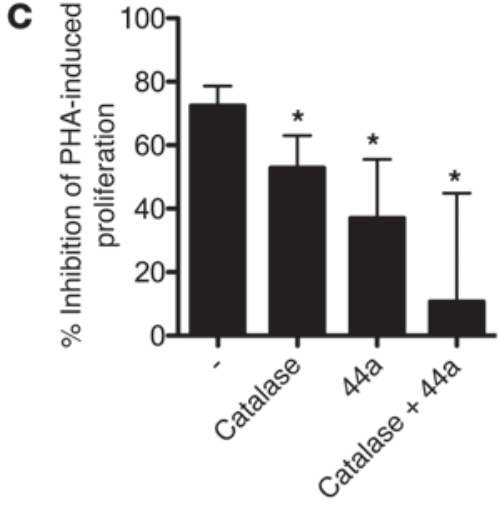

\section{Figure 5}

Mechanism of neutrophil-induced suppression of T cell proliferation. (A) Soluble mediators of T cell inhibition. CD62 Ldim neutrophils were added in a 2:1 ratio to PHA-stimulated $(10 \mu \mathrm{g} / \mathrm{ml})$ PBMCs in the presence or absence of anti-IL-10 $(5 \mu \mathrm{g} / \mathrm{ml})$, TGF- $\beta$ inhibitor LAP $(1 \mu \mathrm{g} / \mathrm{ml})$, or L-arginine $(1 \mathrm{mM})$. Data are presented as mean \pm SEM of 5 independent experiments. (B) Separation of CD62Ldim neutrophils and PBMCs. Neutrophils and T cells were separated by a membrane using a Thinsert system (MS). Neutrophils were placed in the upper compartment in a 2:1 ratio, and PBMCs were placed in the lower. These data were compared with nonseparated neutrophils and PBMCs (-). Data are expressed as mean \pm SEM of 4 individual experiments. (C) CD62L dim neutrophils were added in a 2:1 ratio to PHA- stimulated (10 $\mu \mathrm{g} / \mathrm{ml})$ PBMCs in the presence or absence of Mac-1-blocking antibody $44 \mathrm{a}(10 \mu \mathrm{g} / \mathrm{ml})$ and/or catalase $(4,000 \mathrm{U} / \mathrm{ml})$. As a control, 44a and catalase were also added to PBMCs without adding neutrophils; data were corrected for this control. Data are presented as mean \pm SEM of 7 independent experiments. (D) Cocultures contained PBMCs with or without FACS-sorted neutrophils subsets or neutrophils from before LPS $(t=0)$. Cocultures were stimulated with PHA $(10 \mu \mathrm{g} / \mathrm{ml})$ and were incubated in culture medium containing Amplex Red $(25 \mu \mathrm{M})$ and HRP $(0.25 \mathrm{U} / \mathrm{ml})$. Fluorescence after reduction of Amplex Red was measured over a period of 8 hours. As a positive control, PAF (10-6 M) and fMLF (10-6 M) were added to the culture. One representative experiment of 3 is depicted. ${ }^{*} P<0.05$.

morphology, which implies increased maturation compared with that of normal blood neutrophils. In addition, we believe neutrophils in this subset are characterized by a unique phenotype (CD62L $\left.\mathrm{L}^{\mathrm{dim}} / \mathrm{CD} 16^{\text {bright }} / \mathrm{CD} 11 \mathrm{~b}^{\text {bright}} / \mathrm{CD} 54^{\text {bright }}\right)$, which distinguishes them from classically short-term activated neutrophils (CD62 $\mathrm{L}^{\mathrm{dim}} /$ CD16 $6^{\text {bright }} / \mathrm{CD} 11 b^{\text {bright }} / \mathrm{CD} 54^{\mathrm{dim}}$ ).

Importantly, we could not induce a similar Mac-1-dependent suppressive phenotype by ex vivo activation of normal neutrophils with various proinflammatory and antiinflammatory stimuli (Supplemental Figure 5). There was some suppression of proliferation after stimulation with AMLF, LPS, and IFN- $\gamma$ plus TNF. However, this suppression was not dependent on Mac-1, as the blocking antibody 44a did not counteract the suppression. Most likely, in vitro neutrophil activation led to an extracellular respiratory burst, resulting in $\mathrm{T}$ cell suppression.

The finding that suppressive neutrophils could not be induced in vitro makes it tempting to speculate that homeostatic blood neutrophils lack a putative functional instruction induced in the tissues. This hypothesis is supported by the fact that inflammation induces immunological stress, and its mediators, such as glucocorticoids and catecholamines, can mobilize mature neutrophils (32). Apparently, it is not possible to mimic such instruction and maturation in the tissues in vitro, as neutrophils ex vivo undergo rapid apoptosis within 24 hours. In vivo, on the other hand, the half-life of circulating neutrophils is much longer (approximately 3.75 days), and neutrophil tissue half-life is estimated to be 6- to 15 -times longer than that of circulating neutrophils $(33,34)$.

The neutrophils released after systemic LPS challenge displayed regulatory properties. This is in line with an emerging concept (35). Recently, more regulatory functions of neutrophils have been described. Murine neutrophils have been shown to produce IL-10, impairing the antimicrobial defense (36). In addition, in various murine models of cancer, sepsis, and transplantation, neutrophils were found to be part of MDSCs. This heterogeneous group of cells, suppressing lymphocyte activation, consists mainly of immature neutrophils and monocytes. Suppression required arginase I or $\operatorname{ROS}(8,37,38)$. In humans with metastatic cancer disease, arginase I-mediated suppression of lymphocytes was reported (10, 11). Arginase I depletes the microenvironment of L-arginine, which is essential for various $\mathrm{T}$ cell functions. However, the suppressive neutrophils in this study inhibited $\mathrm{T}$ cell proliferation via local production of $\mathrm{H}_{2} \mathrm{O}_{2}$. Several mechanisms have been suggested for T cell suppression by $\mathrm{H}_{2} \mathrm{O}_{2}$, including changes in the surface thiol expression, NF- $\mathrm{\kappa B}$ activation, and oxidation of the actin remodeling protein cofilin $(25,26,39,40)$. These experiments relied on the addition of various concentrations of $\mathrm{H}_{2} \mathrm{O}_{2}$ to the culture media. 
A

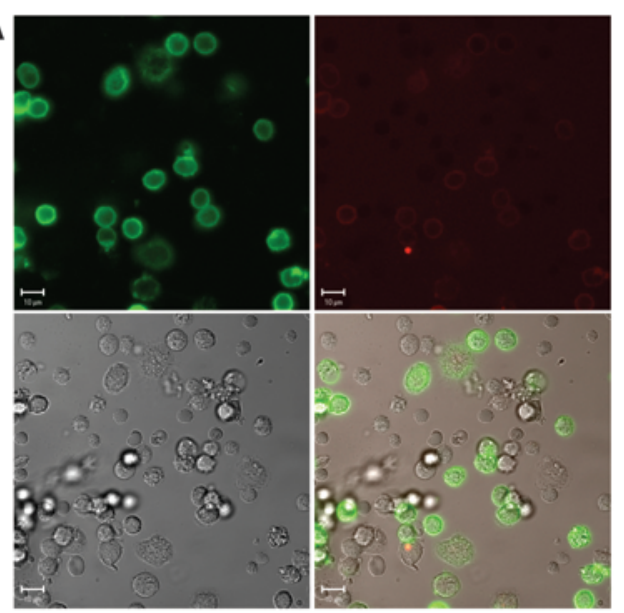

B
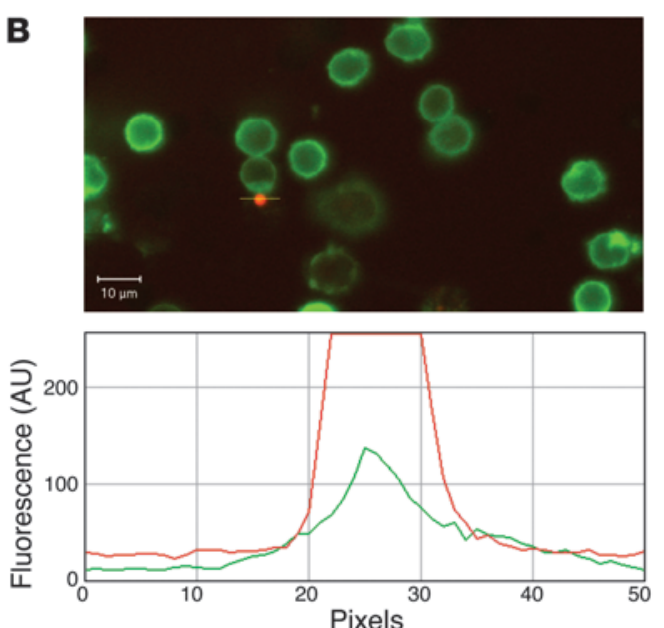

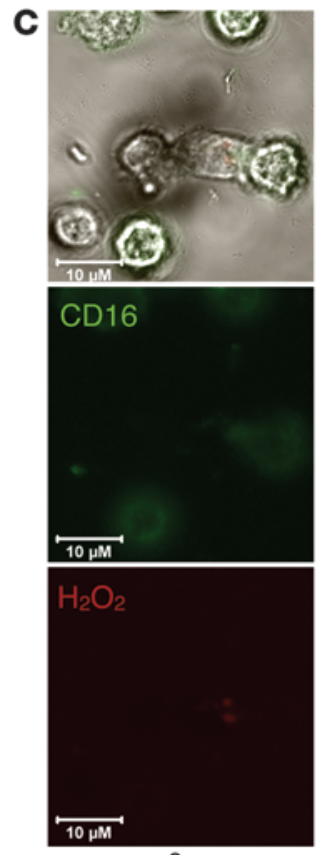

0

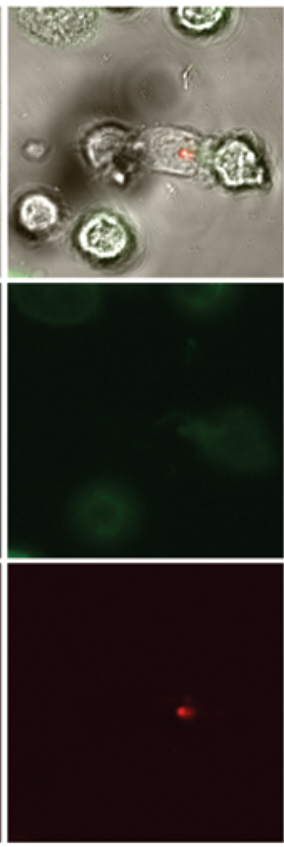

$48 \mathrm{~s}$

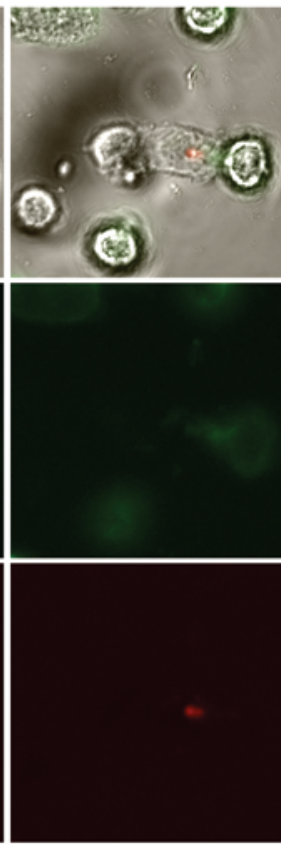

$1 \min 36 \mathrm{~s}$

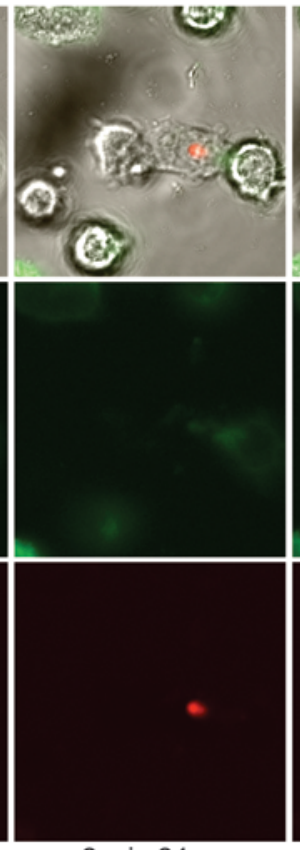

$2 \min 24 s$

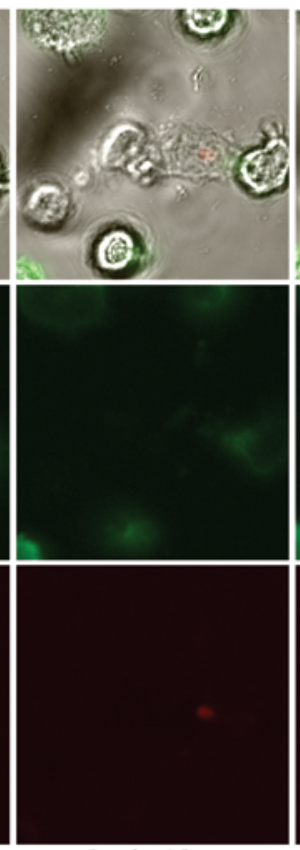

$3 \min 12 \mathrm{~s}$

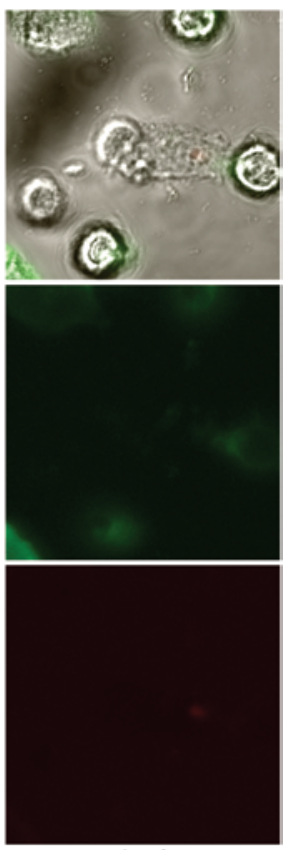

$4 \min$

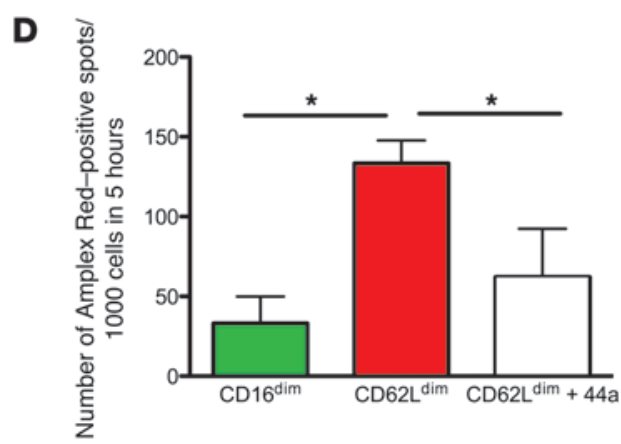

\section{Figure 6}

Visualization of neutrophil-lymphocyte interactions. CD62L dim-sorted neutrophils stained with CD16 FITC were added in a 2:1 ratio to unlabeled PBMCs and stimulated with PHA $(10 \mu \mathrm{g} / \mathrm{ml})$. Cells were incubated in culture medium containing Amplex Red (50 $\mu \mathrm{M})$ and HRP $(0.5 \mathrm{U} / \mathrm{ml})$. Images were acquired using a Zeiss LSM510 Meta microscope. (A) Neutrophil-lymphocyte interaction with a localized Amplex Red signal indicative for local production of $\mathrm{H}_{2} \mathrm{O}_{2}$. (B) Same interaction as in A, showing that the Amplex Red signal colocalized with the CD16-labeled neutrophil membrane. The green line represents CD16; the red line represents $\mathrm{H}_{2} \mathrm{O}_{2}$. (C) Time-lapse image of a neutrophil-lymphocyte interaction. See Supplemental Video 1 for the full video. Representative examples are shown of 4 independent experiments. Original magnification, $\times 40$ (A-C). (D) Quantification of local production of $\mathrm{H}_{2} \mathrm{O}_{2}$ spots in time-lapse images. Time-lapse images were made by deconvolution microscopy (Applied Precision DeltaVision Core Imaging System; the camera used was a Cascade EMCCD). CD62 Lim- and CD16 ${ }^{\text {dim-sorted neu- }}$ trophils stained with calcein were added in a 2:1 ratio to unlabeled lymphocytes and stimulated with PHA $(10 \mu \mathrm{g} / \mathrm{ml})$. Cells were incubated in culture medium containing Amplex UltraRed $(50 \mu \mathrm{M})$ and HRP $(0.5 \mathrm{U} / \mathrm{ml})$. In one of the conditions, Mac-1-blocking antibody $44 \mathrm{a}$ was added. The number of $\mathrm{H}_{2} \mathrm{O}_{2}$-positive spots were counted. Data are presented as mean \pm SEM of 3 independent experiments. ${ }^{*} P<0.05$. 

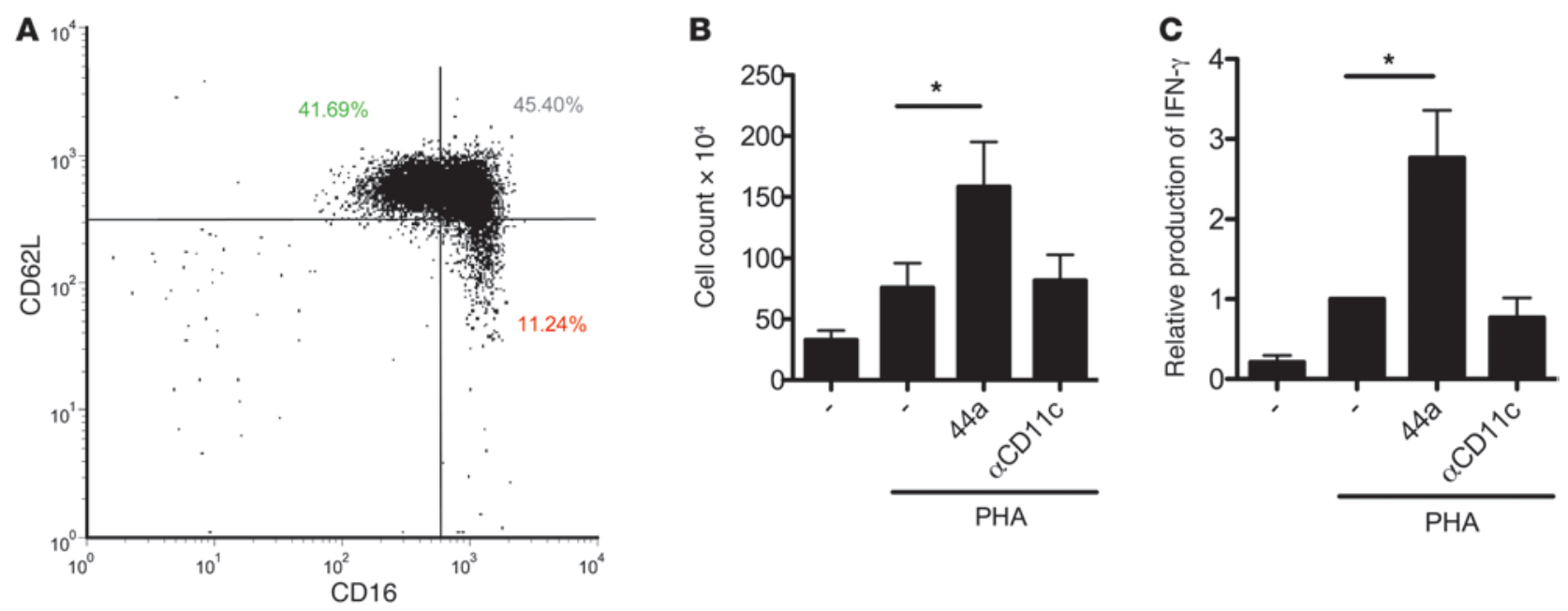

Figure 7

Suppression of T cell proliferation in severely injured patients. (A) Blood was drawn from severely injured patients immediately after admission in the hospital. Total leukocytes were stained for CD16 and CD62L. A CD62Ldim subset of neutrophils was seen similar to the subset found 3 hours after LPS. Numbers indicate the percentages of cells in each gate. (B) Total leukocytes from severely injured patients were stimulated with PHA $(10 \mu \mathrm{g} / \mathrm{ml})$ and incubated in the presence or absence (-) of blocking antibodies to Mac-1 (44a) or CD11c (clone 3.9) for 5 days. After 5 days of incubation, total leukocytes were counted. Groups were compared using a paired samples $t$ test. Data are presented as mean \pm SEM of 4 independent experiments. (C) IFN- $\gamma$ concentration was measured by ELISA in the supernatants of the 5-day cultures. Data are depicted as relative increase compared with that of PHA only. Groups were compared using a paired samples $t$ test. Data are presented as mean \pm SEM of 5 independent experiments. ${ }^{*} P<0.05$.

In our model, we observed short, very localized, and asynchronous production of $\mathrm{H}_{2} \mathrm{O}_{2}$ in an immunological synapse. ROS can rapidly be scavenged by an abundance of molecules, resulting in a very short half-life. The release of $\mathrm{H}_{2} \mathrm{O}_{2}$ in an immunological synapse, as reported in this study, might therefore increase the efficiency of $\mathrm{H}_{2} \mathrm{O}_{2}$-mediated immune regulation. This local release of ROS onto the surface of T cells, the lack of detectable neutrophil extracellular ROS release (Figure 5D), and the absence of increased T cell apoptosis after neutrophils induced suppression (Figure 3D) suggest that neutrophils are capable of releasing a limited amount of ROS for immune regulatory purposes. The role of ROS in immune tolerance has been shown previously in models of chronic inflammation (39). However, this latter study focused on macrophages, because, in contrast to neutrophils, these cells were thought to release limited amounts of immunoregulatory ROS. Additionally, studies on the importance of cellular contact have focused on the interaction between lymphocytes and APCs. Suppressive characteristics have been reported for dendritic cells, which prevent full $\mathrm{T}$ cell activation through active Mac-1 (41). A role for ROS in this study was not evaluated.

It is tempting to speculate that the mechanism mediated by Mac-1 and ROS in immune regulation is not restricted to neutrophils and may represent a more generalized mechanism for the immune regulation by myeloid cells in humans, as both ROS and Mac-1 have separately been implicated in immune regulation by APCs $(39,41)$. In addition, the role of $\mathrm{H}_{2} \mathrm{O}_{2}$ in the suppression of $\mathrm{T}$ cell activation described in this paper might in part explain the hyperinflammatory phenotype observed in patients suffering from chronic granulomatous disease, who lack NADPH oxidase (42). Despite the fact that neutrophil-T cell interactions have been described in lymphoid organs in mice $(43,44)$, it is still unknown whether human neutrophils enter lymphoid organs and come into close contact with $T$ cells. In many acute and chronic inflammatory conditions, however, neutrophils and $\mathrm{T}$ cells are present in the tissues. As neutrophilic inflammation frequently results in tissue damage, neutrophil-induced inhibition of $\mathrm{T}$ cell proliferation might be essential to limit $\mathrm{T}$ cell activation and, thereby, maintain tolerance in these inflammatory conditions. The exact role for neutrophils in immune tolerance in humans remains to be examined; however, it is clear that neutrophil association with solid tumors is detrimental for disease outcome, possibly through suppressing immunogenic antitumor responses.

In conclusion, we provide evidence of what we believe to be a newly identified subset of human neutrophils, which can potently suppress $\mathrm{T}$ cell responses. Identification of this neutrophil subset in human inflammation and the role of neutrophil Mac- 1 integrin might provide novel therapeutic strategies to target immune suppression in inflammation and cancer.

\section{Methods}

Subjects and study design. Experiments were part of several endotoxin trials (NCT00513110, NCT00783068, NCT00785018, NCT00916448, NCT01374711; www.clinicaltrials.gov). Subjects were enrolled after screening and prehydrated $(43,44)$. US reference E. coli endotoxin (lot Ec-5; Center for Biologic Evaluation and Research, Food and Drug Administration, Bethesda, Maryland, USA) was used in this study. Endotoxin was reconstituted in $5 \mathrm{ml}$ saline and injected as single i.v. bolus during 1 minute at $t=0$. Blood samples anticoagulated with sodium heparin were taken from the arterial catheter. Patients with severe injuries (an injury severity score of more than 15) were included, with an expected intensive care stay of longer than 3 days. Blood was sampled within 12 hours of admission to the emergency department.

Reagents. HSA and pasteurized plasma solution were purchased from the Central Laboratory of the Netherlands (Sanquin). Isolation buffer contained PBS supplemented with pasteurized plasma solution (10\%) 
and trisodium citrate $(0.4 \%[\mathrm{w} / \mathrm{v}])$. Incubation buffer contained $20 \mathrm{mM}$ HEPES, $132 \mathrm{mM} \mathrm{NaCl}, 6 \mathrm{mM} \mathrm{KCl}, 1 \mathrm{mM} \mathrm{MgSO}_{4}, 1.2 \mathrm{mM} \mathrm{KH}_{2} \mathrm{PO}_{4}$, supplemented with $5 \mathrm{mM}$ glucose, $1.0 \mathrm{mM} \mathrm{CaCl}_{2}$, and $0.5 \%$ (w/v) HSA.

1-Methyl tryptophan was provided by R. Lutter (Department of Experimental Immunology and Pulmonology, Amsterdam Medical Center, Amsterdam, The Netherlands). PHA (PHA-P), latency-associated peptide (LAP), fMLF, PAF, PMA, dihidrorhodamine (DHR) (1), arginine, and HRP were purchased from Sigma-Aldrich. Amplex Red and Amplex UltraRed were purchased from Molecular Probes. CD14 microbeads was purchased from Miltenyi Biotec. Tetanus toxoid was purchased from NVI. Ionomycin and Brefeldin A were purchased from Invitrogen. Human erythrocyte catalase was purchased from Meridian Life Science Inc. (BIODESIGN International). Fixation/Permeabilization Concentrate, Fixation/Permeabilization Diluent, and Permeabilization Buffer were purchased from eBioscience. All other materials were reagent grade.

Antibodies. Unlabeled antibodies were as follows: function blocking antibody $44 \mathrm{a}$ (anti- $\alpha \mathrm{M}$ integrin) was isolated from supernatant of the hybridoma obtained from ATCC; function blocking CD11c (clone 3.9) was obtained from Biolegend; CD3 (clone CLB-T3/4E, 1XE) and CD28 (clone CLB-CD28/1, 15E8) were obtained from Sanquin; and anti-IL-10 (clone 12G8) was obtained from Schering-Plough Research (InstituteKenilworth). Monoclonal antibodies used for flow cytometry are as follows: CD4 perCP (clone L200), CD8 APC (clone SK1), IFN- $\gamma$ FITC/IL4 PE (clone 25723.11/3010.211), CD16 Alexa Fluor 647 (clone 3G8), CD62L PE (SK11), CD62L FITC (DREG56), CD11c APC (clone S-HCL-3), and annexin V-PE were purchased from BD. CD11b PE (clone 2LPM19c) was purchased from DAKO. CD16 FITC (clone LNK16) was purchased from Serotec. Other antibodies used are stated in Supplemental Table 1.

Neutrophil flow cytometry and cell counts. Erythrocytes were lysed in isotonic ice-cold $\mathrm{NH}_{4} \mathrm{Cl}$ solution followed by centrifugation at $4^{\circ} \mathrm{C}$. After lysis, total leukocytes were stained with antibodies for 30 minutes at $4^{\circ} \mathrm{C}$ in isolation buffer. Cells were washed before analysis on a FACSCalibur (Becton Dickenson) or sorted on a FACSAria (Becton Dickenson), FACSVantage (Becton Dickenson), or MoFlo Astrios (Beckman Coulter Inc.). Total leukocyte counts were counted in whole blood using Cell-Dyn 1800 cell counter (Abbot Diagnostics). Using the percentages found by flow cytometry and the absolute leukocyte count, the absolute numbers of circulating neutrophil subsets were calculated. For annexin V staining, PBMCs were prestained with CD3. Afterward, cells were stained with annexin PE in annexin-binding buffer.

Granulocyte and PBMC isolation. Cells were isolated as described previously (45). In short, cells were separated by centrifugation over Ficoll-Paque PLUS (GE Healthcare) for 20 minutes at $900 \mathrm{~g}$. The mononuclear cell layer was removed. The erythrocytes in the granulocyte layer were lysed as described in the Neutrophil flow cytometry and cell counts section above. In some experiments, monocytes were depleted using CD14 MACS microbeads.

ROS. Production of ROS was studied by staining total leukocytes with $\mathrm{CD} 16$ and CD62L and loading with DHR for 15 minutes at $37^{\circ} \mathrm{C}$. After stimulation with $\mathrm{AMLF}$ or $\mathrm{PAF} / \mathrm{fMLF}$, the relative increase in ROS production was determined in both neutrophil subsets by flow cytometry. In addition, isolated neutrophils and PBMCs were incubated in a 96-well plate in the presence of PHA $(10 \mu \mathrm{g} / \mathrm{ml})$, Amplex Red $(25 \mu \mathrm{M})$, and HRP $(0.25$ $\mathrm{U} / \mathrm{ml}$ ). Production of fluorescent resorufin, formed from Amplex Red in the presence of HRP after peroxidation, was measured during 8 hours at $37^{\circ} \mathrm{C}$ using a fluoro-luminometer FluostarOptima (BMG LABTECH).

$T$ cell proliferation. Experiments were performed in IMDM culture medium supplemented with $5 \%$ pooled human $\mathrm{AB}$ serum (Cambrex), penicillin (100 IU/ml; Gibco, Invitrogen), streptomycin (100 mg/ml; Gibco, Invitrogen), and glutamine (1 mM; Gibco, Invitrogen). Proliferation at 96 hours was measured by assessing $[3 \mathrm{H}]$ thymidine incorporation $(1 \mathrm{mCi} /$ well [Amersham]); $[3 \mathrm{H}]$ thymidine was added during the last 18 hours of culturing. Proliferative responses are expressed as the mean $[3 \mathrm{H}]$ thymidine incorporation, which is measured as counts per minute of triplicate wells. For the solubility experiments, Thinserts (Greiner) were used, 24-well inserts with a pore size of $0.4 \mu \mathrm{M}$. In experiments with inhibitors or blocking antibodies, $\mathrm{T}$ cell proliferation was always corrected for PBMCs alone with the same inhibitor or blocking antibody.

Cytokine ELISA. IFN- $\gamma$ and IL-13 production was measured by a sandwich ELISA according to the manufacturers' recommendations (Sanquin). The detection limit was $2 \mathrm{pg} / \mathrm{ml}$.

PBMCflow cytometry stainings. After 2 days of coculture, PBMCs were stimulated with either control medium or $20 \mathrm{ng} / \mathrm{ml} \mathrm{PMA}$ and $3 \mu \mathrm{g} / \mathrm{ml}$ ionomycin for 6 hours; $10 \mu \mathrm{g} / \mathrm{ml}$ Brefeldin A was added after 1 hour. Cells were stained on ice for surface markers CD4 and CD8, fixed, permeabilized, and stained with anti-IFN- $\gamma$ FITC and anti-IL-4 PE antibody at room temperature. Cells were washed before analysis on a FACSCalibur (Becton Dickenson).

Microscopy. Cocultures of sorted CD62 $\mathrm{L}^{\mathrm{dim}}$ neutrophils (labeled with CD16 FITC) and unlabeled PBMCs in the presence of PHA $(10 \mu \mathrm{g} / \mathrm{ml})$ were supplemented with $50 \mu \mathrm{M}$ Amplex Red and $0.5 \mathrm{U} / \mathrm{ml}$ HRP. During the course of 4 hours, neutrophil-lymphocyte interactions were imaged with a Zeiss LSM510 Meta microscope. For quantification, CD62 $\mathrm{L}^{\mathrm{dim}}$ - and

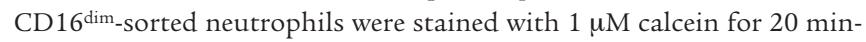
utes at $37^{\circ} \mathrm{C}$. Instead of Amplex Red, Amplex UltraRed $(50 \mu \mathrm{M})$ was used for these experiments. The interactions were imaged for an average of 3 hours using a deconvolution microscope (Applied Precision DeltaVision Core Imaging System; the camera used was a Cascade EMCCD). Afterward interactions were counted by eye; the person counting the interactions was blinded for the different conditions.

Statistics. Data were analyzed using Graphpad Prism 4.0. Repeated-measures ANOVA was used to compare different time points. A Wilcoxon signed-rank test or a 2-tailed paired samples $t$ test was used to compare groups. A $P$ value of less than 0.05 was considered significant.

Study approval. The study protocol concerning the human endotoxemia challenges was approved by the Ethics Committee of the Radboud University Nijmegen Medical Centre and complies with the Declaration of Helsinki and the Good Clinical Practice guidelines. Volunteers gave written informed consent. The Ethics Committee of the University Medical Center Utrecht approved the study protocol concerning the patients suffering severe injuries included in this study. Patients gave informed consent after sampling of the blood according to the research protocol.

\section{Acknowledgments}

The authors would like to thank Bart Ramakers, Matthijs Kox, Jan Pompe, Mirrin Dorresteijn, Jenneke Leentjens, and Tijn Bouw for performing the endotoxin challenges in human volunteers. We are grateful to Jan van der Linden, Jeroen Langereis, and Adele Lo Tam Loi for performing experiments. We thank Gerrit Spierenburg, Koos Gaiser, Ger Arkesteijn, Corneli van Aalst, and Deon Kanters for the help with FACS sorting. We thank René Lutter for the gifts of reagents and Jolanda de Vries for the use of the laboratory facilities in Nijmegen. We are grateful for the expertise and assistance of the Cell Microscopy Center Utrecht. Finally, we thank Linde Meyaard and Dirk Roos for critically reading the manuscript. This study was performed within the framework of the Dutch Top Institute Pharma project T1-201-1 (Transition of systemic inflammation into multi-organ pathology). This is a collaboration between 3 universities (University Medical Center Utrecht, University Medical Center Groningen, and Maastricht University), 4 pharmaceutical companies (AstraZeneca, GlaxoSmithKline, Nycomed BV, and Danone Research), and the Dutch government. In addition, this study was 
supported by an unrestricted research grant from GlaxoSmithKline and a grant from the Dutch Asthma foundation (NAF 3.2.10.052).

Received for publication March 14, 2011, and accepted in revised form October 26, 2011.

1. Gabrilovich DI, Nagaraj S. Myeloid-derived suppressor cells as regulators of the immune system. Nat Rev Immunol. 2009;9(3):162-174.

2. Haile LA, et al. Myeloid-derived suppressor cells in inflammatory bowel disease: a new immunoregulatory pathway. Gastroenterology. 2008;135(3):871-881.

3. Mencacci A, et al. CD80+Gr-1+ myeloid cells inhibit development of antifungal Th1 immunity in mice with candidiasis. J Immunol. 2002;169(6):3180-3190.

4. Morecki S, Gelfand Y, Yacovlev E, Eizik O, Shabat Y, Slavin S. CpG-induced myeloid CD $11 \mathrm{~b}+\mathrm{Gr}-1+$ cells efficiently suppress $\mathrm{T}$ cell-mediated immunoreactivity and graft-versus-host disease in a murine model of allogeneic cell therapy. Biol Blood Marrow Transplant. 2008;14(9):973-984.

5 . Movahedi K, et al. Identification of discrete tumorinduced myeloid-derived suppressor cell subpopulations with distinct $\mathrm{T}$ cell-suppressive activity. Blood. 2008;111(8):4233-4244.

6. Bhardwaj N. Harnessing the immune system to treat cancer. J Clin Invest. 2007;117(5):1130-1136.

7. Nagaraj S, Gabrilovich DI. Myeloid-derived suppressor cells in human cancer. Cancer J. 2010; 16(4):348-353.

8. Youn JI, Nagaraj S, Collazo M, Gabrilovich DI. Subsets of myeloid-derived suppressor cells in tumorbearing mice. J Immunol. 2008;181(8):5791-5802.

9. Almand B, et al. Increased production of immature myeloid cells in cancer patients: a mechanism of immunosuppression in cancer. J Immunol. 2001;166(1):678-689.

10. Rodriguez PC, et al. Arginase I-producing myeloidderived suppressor cells in renal cell carcinoma are a subpopulation of activated granulocytes. Cancer Res. 2009;69(4):1553-1560.

11. Zea AH, et al. Arginase-producing myeloid suppressor cells in renal cell carcinoma patients: a mechanism of tumor evasion. Cancer Res. 2005; 65(8):3044-3048.

12. Rodriguez PC, Quiceno DG, Ochoa AC. L-arginine availability regulates T-lymphocyte cell-cycle progression. Blood. 2007;109(4):1568-1573.

13. Corzo CA, et al. Mechanism regulating reactive oxygen species in tumor-induced myeloid-derived suppressor cells. J Immunol. 2009;182(9):5693-5701.

14. Kusmartsev S, et al. Reversal of myeloid cellmediated immunosuppression in patients with metastatic renal cell carcinoma. Clin Cancer Res. 2008;14(24):8270-8278.

15. Delano MJ, et al. MyD88-dependent expansion of an immature GR-1(+)CD11b(+) population induces $\mathrm{T}$ cell suppression and Th2 polarization in sepsis. J Exp Med. 2007;204(6):1463-1474.

16. Hotchkiss RS, Coopersmith CM, McDunn JE, Ferguson TA. The sepsis seesaw: tilting toward immunosuppression. Nat Med. 2009;15(5):496-497.

Address correspondence to: Leo Koenderman, Department of Respiratory Medicine, University Medical Center Utrecht, Heidelberglaan 100, 3584CX, Utrecht, The Netherlands. Phone: 31.88.7557255; Fax: 31.88.7555415; E-mail: 1.koenderman@ umcutrecht.nl.

17. Limaye AP, et al. Cytomegalovirus reactivation in critically ill immunocompetent patients. JAMA. 2008;300(4):413-422.

18. Luyt CE, et al. Herpes simplex virus lung infection in patients undergoing prolonged mechanical ventilation. Am J Respir Crit Care Med. 2007;175(9):935-942.

19. Pickkers P, Dorresteijn MJ, Bouw MP, van der Hoeven JG, Smits P. In vivo evidence for nitric oxide-mediated calcium-activated potassium-channel activation during human endotoxemia. Circulation. 2006;114(5):414-421

20. Pillay J, et al. Functional heterogeneity and differential priming of circulating neutrophils in human experimental endotoxemia. J Leukoc Biol. 2010;88(1):211-220.

21. Fortunati E, Kazemier KM, Grutters JC, Koenderman L, Van den Bosch JM. Human neutrophils switch to an activated phenotype after homing to the lung irrespective of inflammatory disease. Clin Exp Immunol. 2009;155(3):559-566.

22. Makarenkova VP, Bansal V, Matta BM, Perez LA, Ochoa JB. CD11b+/Gr-1+ myeloid suppressor cells cause $\mathrm{T}$ cell dysfunction after traumatic stress. J Immunol. 2006;176(4):2085-2094.

23. Kusmartsev SA, Li Y, Chen SH. Gr-1+ myeloid cells derived from tumor-bearing mice inhibit primary $\mathrm{T}$ cell activation induced through $\mathrm{CD} 3 / \mathrm{CD} 28$ costimulation. J Immunol. 2000;165(2):779-785.

24. Roos D, Winterbourn CC. Immunology. Lethal weapons. Science. 2002;296(5568):669-671.

25. Gelderman KA, Hultqvist M, Holmberg J, Olofsson P, Holmdahl R. T cell surface redox levels determine $\mathrm{T}$ cell reactivity and arthritis susceptibility. Proc Natl Acad Sci U S A. 2006;103(34):12831-12836.

26. Klemke M, Wabnitz GH, Funke F, Funk B, Kirchgessner H, Samstag Y. Oxidation of cofilin mediates $\mathrm{T}$ cell hyporesponsiveness under oxidative stress conditions. Immunity. 2008;29(3):404-413.

27. van Spriel AB, et al. Mac-1 (CD11b/CD18) is essential for $\mathrm{Fc}$ receptor-mediated neutrophil cytotoxicity and immunologic synapse formation. Blood. 2001;97(8):2478-2486.

28. Springer TA. Adhesion receptors of the immune system. Nature. 1990;346(6283):425-434.

29. Gallin JI. Human neutrophil heterogeneity exists, but is it meaningful? Blood. 1984;63(5):977-983.

30. Otten MA, et al. Immature neutrophils mediate tumor cell killing via IgA but not IgG Fc receptors. Jimmunol. 2005;174(9):5472-5480.

31. Taneja R, Sharma AP, Hallett MB, Findlay GP, Morris MR. Immature circulating neutrophils in sepsis have impaired phagocytosis and calcium signaling. Shock. 2008;30(6):618-622.

32. Nakagawa M, Terashima T, D’Yachkova Y, Bondy GP, Hogg JC, van Eeden SF. Glucocorticoidinduced granulocytosis: contribution of marrow release and demargination of intravascular granulocytes. Circulation. 1998;98(21):2307-2313.

33. Cheretakis C, Leung R, Sun CX, Dror Y, Glogauer $M$. Timing of neutrophil tissue repopulation predicts restoration of innate immune protection in a murine bone marrow transplantation model. Blood. 2006;108(8):2821-2826.

34. Pillay J, et al. In vivo labeling with $2 \mathrm{H} 2 \mathrm{O}$ reveals a human neutrophil lifespan of 5.4 days. Blood. 2010;116(4):625-627.

35. Muller I, Munder M, Kropf P, Hansch GM. Polymorphonuclear neutrophils and $\mathrm{T}$ lymphocytes: strange bedfellows or brothers in arms? Trends Immunol. 2009;30(11):522-530.

36. Zhang X, Majlessi L, Deriaud E, Leclerc C, LoMan R. Coactivation of Syk kinase and MyD88 adaptor protein pathways by bacteria promotes regulatory properties of neutrophils. Immunity. 2009;31(5):761-771.

37. Jacobsen LC, Theilgaard-Monch $\mathrm{K}$, Christensen EI, Borregaard N. Arginase 1 is expressed in myelocytes/metamyelocytes and localized in gelatinase granules of human neutrophils. Blood. 2007;109(7):3084-3087.

38. Munder M, et al. Arginase I is constitutively expressed in human granulocytes and participates in fungicidal activity. Blood. 2005;105(6):2549-2556.

39. Gelderman KA, et al. Macrophages suppress T cell responses and arthritis development in mice by producing reactive oxygen species. J Clin Invest. 2007;117(10):3020-3028.

40. Schoonbroodt S, et al. Crucial role of the aminoterminal tyrosine residue 42 and the carboxylterminal PEST domain of I kappa B alpha in NFkappa B activation by an oxidative stress. J Immunol. 2000;164(8):4292-4300.

41. Varga G, et al. Active MAC-1 (CD11b/CD18) on DCs inhibits full T-cell activation. Blood. 2007; 109(2):661-669.

42. Rahman FZ, Marks DJ, Hayee BH, Smith AM, Bloom SL, Segal AW. Phagocyte dysfunction and inflammatory bowel disease. Inflamm Bowel Dis. 2008;14(10):1443-1452

43. Abadie V, et al. Neutrophils rapidly migrate via lymphatics after Mycobacterium bovis BCG intradermal vaccination and shuttle live bacilli to the draining lymph nodes. Blood. 2005;106(5):1843-1850.

44. Maletto BA, et al. Presence of neutrophil-bearing antigen in lymphoid organs of immune mice. Blood. 2006;108(9):3094-3102.

45. Verploegen S, van Leeuwen CM, van Deutekom HW, Lammers JW, Koenderman L, Coffer PJ. Role of $\mathrm{Ca} 2+/$ calmodulin regulated signaling pathways in chemoattractant induced neutrophil effector functions. Comparison with the role of phosphotidylinositol-3 kinase. Eur J Biochem. 2002;269(18):4625-4634. 